\title{
Clinical Pharmacokinetic and Bioequivalence Studies of Two Brands of Cephradine in Healthy Korean Using HPLC Method
}

\author{
Hyun-Jin Kim, Shin-Hee Kim, Semi Kim, Jae-Sung Ahn, Ju-Seop Kang* \\ Department of Pharmacology, Clinical Pharmacology Laboratory, Division of Molecular Therapeutics Development, \\ Hanyang Biomedical Research Institute, College of Medicine, Hanyang University, Seoul, South Korea \\ Email: *jskang@hanyang.ac.kr
}

How to cite this paper: Kim, H.-J., Kim, S.-H., Kim, S., Ahn, J.-S. and Kang, J.-S. (2018) Clinical Pharmacokinetic and Bioequivalence Studies of Two Brands of Cephradine in Healthy Korean Using HPLC Method. Pharmacology \& Pharmacy, 9, 279-292.

https://doi.org/10.4236/pp.2018.97022

Received: June 29, 2018

Accepted: July 28, 2018

Published: July 31, 2018

Copyright $\odot 2018$ by authors and Scientific Research Publishing Inc. This work is licensed under the Creative Commons Attribution International License (CC BY 4.0).

http://creativecommons.org/licenses/by/4.0/ Open Access

\begin{abstract}
The goal of our research was to compare the pharmacokinetics and evaluate the bioequivalence of two brands of cephradine $500 \mathrm{mg}$ capsules in 24 normal Korean volunteers. The plasma samples were acquired at 13 time points for 8 $\mathrm{h}$ after administration. The concentrations of cephradine in human plasma were measured by a high-performance liquid chromatography (HPLC). Isocratic mobile phase which consisted of acetonitrile, methanol, and $20 \mathrm{mM}$ potassium phosphate $(15 / 5 / 80, \mathrm{v} / \mathrm{v} / \mathrm{v}, \mathrm{pH} 3.48)$ was used to separate the analytical column cosmosil cholester $(250 \times 4.6 \mathrm{~mm}, 3 \mu \mathrm{m})$. Analytes were detected in ultraviolet $(260 \mathrm{~nm})$. The novel analytical method was described as simple sample preparation, a short retention time (less than $6 \mathrm{~min}$ ) and making it suitable for use in clinical trials. Pharmacokinetic parameters, such as $\mathrm{AUC}_{0-t}(20.54$ vs $18.42 \mu \mathrm{g} \cdot \mathrm{h} / \mathrm{mL}), \mathrm{AUC}_{0 \text {-infinity }}(21.22 \mathrm{vs} 19.14 \mu \mathrm{g} \cdot \mathrm{h} / \mathrm{mL}), C_{\max }$ (12.69 vs $12.81 \mu \mathrm{g} / \mathrm{mL}), \mathrm{T}_{\max }(1.22$ vs $0.92 \mathrm{~h}$ ), half-life (1.02 vs $1.13 \mathrm{~h}$ ), extrapolation $(3.22 \%$ vs $3.75 \%)$, and $\operatorname{Ke}\left(0.73\right.$ vs $\left.0.69 \mathrm{~h}^{-1}\right)$ were determined for the reference and test drugs in plasma. Pharmacokinetic parameters with a $90 \%$ confidence interval were $87 \%-95 \%$ for $\mathrm{AUC}_{0-t}$ and $91 \%-115 \%$ for $C_{\max }$. They were satisfied within the bioequivalence range $80 \%-125 \%$ of the KFDA guidelines. Therefore, our HPLC method was well applied in a bioequivalence and pharmacokinetic study of two formulations in normal subjects.
\end{abstract}

\section{Keywords}

Bioequivalence, Cephalosporin Antibiotic, Cephradine, Korean Volunteers, Pharmacokinetics

\section{Introduction}

Cephradine ((6R, 7R)-7-\{[(2R)-2-amino-2-cyclohexa-1, 4-dien-1-ylacetyl $]$ ami- 
no\}-3-methyl-8-oxo-5-thia-1-azabicyclo [4.2.0] oct-2-ene-2-carboxylic acid) is a first generation cephalosporin antibiotic. It has broad spectrum antibacterial activity against gram-positive and gram-negative microorganisms and acts through inhibiting bacterial cell wall synthesis. Cephradine is used to treat upper respiratory infections, ear infections, skin infections, and urinary tract infections. It is rapidly absorbed from the gastrointestinal tract and has low plasma protein binding $(6 \%-20 \%)$ [1]. It is excreted approximately $90 \%$ of the drug which is unchanged by the kidney within $6 \mathrm{~h}$ administration [2]. A daily therapeutic dose of cephradine is 250 - $500 \mathrm{mg}$, and after oral administration of $500 \mathrm{mg}$ of cephradine the maximal plasma concentration $\left(C_{\max }\right)$ is $15.67 \pm 4.21 \mu \mathrm{g} / \mathrm{mL}$ and the time to maximal plasma concentration $\left(\mathrm{T}_{\max }\right)$ is about $1 \mathrm{~h} \mathrm{[3]}$.

Several analytical methods have been reported to measure cephradine in biological fluids. These methods include spectrophotometry [4] [5] [6], spectrofluorimetry [7] [8], luminescence [9] [10], capillary electrophoresis [11], and bioassays [1] [2] [12] [13] [14]. The previous methods often lack sufficient sensitivity and specificity to measure low cephradine concentrations in plasma. Recent studies have used high-performance liquid chromatography (HPLC) [15]-[22] and liquid chromatography tandem mass spectrometry (LC-MS/MS) [23] [24] in order to increase the sensitivity to detect cephradine in biological materials. However, these methods have disadvantages as follows. HPLC methods take a long time and LC-MS/MS methods require the startup costs and highly skilled human resource to perform the assays and manage the instrument. The comparative details of literature are provided in Table 1.

Since the Drug Price Competition and Patent Term Restoration Act were implemented in 1984, the US Food and Drug Administration (FDA) have established bioavailability and bioequivalence requirements for generic substitution [13] [25] [26]. According to the Act, the goal of clinical bioavailability studies is to compare certain pharmacokinetic $(\mathrm{PK})$ parameters of the test and reference products. The current bioequivalence test requires, to declare bioequivalence, the population mean differences in the extent (area under the curve (AUC)) and rate of absorption ( $C_{\max }$ ) between the test and reference formulations do not exceed $20 \%$ [25]. Therefore, our purpose of research was to develop a fast, convenient, and efficient method to analyze biological cephradine levels and use it to measure cephradine concentrations in human plasma samples in the bioequivalence and pharmacokinetic test of 2 brands of cephradine capsules (500 mg) in 24 normal Korean subjects.

Furthermore, we performed a comparison of basic PK parameters such as AUC, $C_{\max }, \mathrm{T}_{\max }$ and $t_{1 / 2}$ of cephradine for Korean subjects and the other races, since previous PK studies [1] [13] [22] [23] [27] of cephradine after oral administration did not considered variable ethnic groups .

\section{Materials and Methods}

\subsection{Chemical and Reagents}

Cephradine and ofloxacin (Internal Standard (IS)) were purchased from Sig- 
ma-Aldrich Co. (St. Louis, Mo, USA). HPLC grade acetonitrile and methanol were purchased from J.T. Baker (Philipsburg, NJ, USA). Water was purified using a Milli-Q purification system (Millipore Co., MA, USA). All other chemicals and solvents were HPLC-analytical grade. The reference drug was Yuhan Cephradine capsules $500 \mathrm{mg}$ (Yuhan Pharm Co. Ltd. Seoul, Korea), and the test drug was Korus cephradine capsules 500 mg (Hankook Korus Pharm Co. Ltd. Seoul, Korea).

\subsection{Instrumentation and Analytical Conditions}

The HPLC system consisted of an isocratic solvent delivery pump (Model 510 pump, Waters Scientific Co., USA), an autosampler (Model 717 Plus, Waters Scientific Co.) an analytical column cosmosil cholester $(250 \times 4.6 \mathrm{~mm}, 3 \mu \mathrm{m})$ (Nacalai, Kyoto, Japan) and a variable wavelength ultraviolet detector (Model 486 Tunable Absorbance Detector, Waters Scientific Co.) set at $260 \mathrm{~nm}$. Data was acquired and processed with Empower 3.0 software. The mobile phase consisted of acetonitrile, methanol, and $20 \mathrm{mM}$ potassium phosphate (15/5/80, $\mathrm{v} / \mathrm{v} / \mathrm{v}, \mathrm{pH} 3.48$ ). The flow rate of the mobile phase was $1.3 \mathrm{~mL} / \mathrm{min}$ and a sample volume of $50 \mu \mathrm{L}$ was injected into the chromatography system.

\subsection{Preparation of Standards and Plasma Samples}

Primary stock solutions of cephradine and IS were prepared in 50\% aqueous methanol (1:1 methanol/water, v/v) to final concentrations of $1 \mathrm{mg} / \mathrm{mL}$ and 200 $\mu \mathrm{g} / \mathrm{mL}$, respectively, and both were kept at $-70^{\circ} \mathrm{C}$. A set of seven non-zero calibration standards, ranging from $0.3 \sim 50 \mu \mathrm{g} / \mathrm{mL}$, was prepared for blank human plasma with an appropriate amount of cephradine. The quality control (QC) samples were prepared in blank plasma at cephradine concentrations of 0.3 (Lower Limit of Quantification (LLOQ)), 1 (low-middle), 10 (high-middle) and $50 \mu \mathrm{g} / \mathrm{mL}$ (high). Blank plasma was tested before spiking, to ensure that there was no endogenous interference before measuring the retention times of cephradine and IS. Frozen human plasma was thawed at room temperature and centrifuged at $3000 \mathrm{rpm}$ for $10 \mathrm{~min}$ at $4^{\circ} \mathrm{C}$ to precipitate the sediment. A $500-\mu \mathrm{L}$ aliquot of plasma was transferred to a screw cap glass tube with $50 \mu \mathrm{L}$ of IS working solution (IS, $200 \mu \mathrm{g} / \mathrm{mL}$ ) and $100 \mu \mathrm{L}$ of acetonitrile/perchloric acid (1:1, $\mathrm{v} / \mathrm{v})$. The mixture was vortexed for $15 \mathrm{sec}$. After centrifugation at 12,000 rpm for $5 \mathrm{~min}$, the supernatant was transferred to a $2 \mathrm{ml}$ tube and centrifuged again. Following centrifugation, the supernatant was transferred to an autosampler vial and an aliquot $(50 \mu \mathrm{L})$ was injected into the HPLC system.

\subsection{Assay Validation}

The assay was validated according to the FDA guidance on validation of bioanalytical methods [28] [29]. Linearity was determined with a linear least-squares regression with $1 / x^{2}$ weighting, performed on the peak area ratios of cephradine and IS versus the cephradine concentrations of the seven blank plasma stan- 
dards. They were randomly selected under controlled conditions and performed of the same extraction method. The sensitivity of the method was expressed as the LLOQ which could be determined with ideal accuracy and precision. The intra- and inter-day accuracy and precision were evaluated by analyzing QC samples which are four cephradine concentrations $(0.3,1.0,10$, and $50 \mu \mathrm{g} / \mathrm{mL})$ in plasma from five replicates on the same day and five consecutive days. Precision was expressed as percent coefficient of variation (\% CV). Accuracy was showed as the percent ratio between the experimental and nominal concentration for each sample. The LLOQ was defined as the lowest concentration of cephradine standard sample, which both the precision and accuracy were within $20 \%$ [28].

\subsection{Bioequivalence and Pharmacokinetic Test in Normal Subjects}

To evaluate the applicability of this method, a randomized, two-period, and crossover design was used to study the pharmacokinetics and bioequivalence of two types of cephradine in 24 normal Korean subjects.

The study was performed according to the World Medical Association Declaration of Helsinki (1997) for biomedical research involving human subjects in 2007 [30] and protocol was confirmed by the Institutional Review Board of Hanyang University Medical Center [31]-[38]. This study design and number of subjects were properly decided to achieve sufficient statistical power to demonstrate BE test according to the Korean FDA Guidelines [39]. The candidate subjects were recruited by internet and paper notice. Enrolling subjects were selected to depend on inclusion criteria of the Korean FDA Guidelines [39]. Twenty-four subjects aged between $19-25$ years $(21.8 \pm 2.4$ years $)$, with heights between $169-180 \mathrm{~cm}(174.0 \pm 3.6 \mathrm{~cm})$ and body weights between $58-83 \mathrm{~kg}$ $(67.3 \pm 6.4 \mathrm{~kg})$ were selected. The subjects were non-alcoholics and disease-free and were assessed as being healthy by a clinical evaluation, including a physical examination and routine clinical laboratory tests including a pregnancy test. One capsule of cephradine (500 mg) was given randomly to 24 healthy subjects. Participants had not taken other medication (including OTC regimens) for two weeks before the study, and refrained from taking other medication during the study period, including the washout period. During each study period, the volunteers were hospitalized at Hanyang University Medical Center at 5:00 pm. and had supper before 8:00 pm. After an overnight fast, they were administered with a test or reference formulation along with $240 \mathrm{~mL}$ water at 7:30 am. Food and beverage were not permitted until $4 \mathrm{~h}$ after dose. A regular lunch was provided at $4 \mathrm{~h}$ after dose and the vital signs of subjects were recorded at times before and after dose. Blood Samples $(9 \mathrm{~mL})$ were collected through a catheter with heparin-containing tubes from a suitable antecubital vein before and at $0.25,0.5$, $0.75,1,1.5,2,2.5,3,4,5,6$, and $8 \mathrm{~h}$ after dose. The samples were centrifuged at $3000 \mathrm{rpm}$ for $10 \mathrm{~min}$ at room temperature and the plasma was stored at $-70^{\circ} \mathrm{C}$ until analyzed [34] [35] [36] [37] [38]. The $C_{\max }$ and $\mathrm{T}_{\max }$ were determined from each subject's plasma level of cephradine versus time plots. Other PK parameters were analyzed and calculated to using PK Solutions software as non-compartmental 
PK model [40]. The area under the plasma concentration versus time curve $\left(\mathrm{AUC}_{0-t}\right)$ was obtained by using the linear trapezoidal rule. The area under the plasma concentration versus time curve extrapolated to infinity $\left(\mathrm{AUC}_{0-\infty}\right)$ was obtained as $\mathrm{AUC}_{0-t}+C_{t} / \mathrm{Ke}$, where $C_{t}$ was the last determining concentration, and Ke was the elimination rate constant. The terminal half-life $\left(t_{1 / 2}\right)$ was calculated as $0.693 / \lambda$. The first moment versus time curve $\left(\mathrm{AUMC}_{0-\infty}\right)$ was obtained by integrating the time $(t)$ of first moment $\left(C_{i} t\right)$

$\left(\mathrm{AUMC}_{\infty}=\int_{0}^{t} C t \cdot t \cdot \mathrm{d} t+C p \cdot \frac{t}{\lambda z^{2}}\right)$. The mean residence time (MRT) of cephradine in the body was calculated as AUMC/AUC, with $\lambda_{z}$ being the Ke [40]. To assess bioequivalence of the test and reference drugs, $\mathrm{AUC}_{0-t}$ and $C_{\max }$ were considered to be the primary variables, and a 2-way ANOVA for the crossover-randomized design was used to estimate the effect of types, term, sequence, and subjects on these parameters [41]. Differences between 2 related parameters were regarded statistically significant at $\mathrm{p}<0.05$. The $90 \%$ confidence intervals $(\mathrm{CI})$ of the geometric means for the individual test/reference ratios (T/R) for $\mathrm{AUC}_{0-p}$ and $C_{\max }$ were calculated, in order to evaluate bioequivalence of the 2 types. The parametric $90 \%$ CIs for the ratios in the $80 \%$ - 125\% range suggested by the Korean Food and Drug Administration (KFDA) were calculated using parametric methods for log-transformed data [41].

\section{Results and Discussion}

\subsection{Analysis}

The molecular structures of cephradine and ofloxacin (IS) were indicated in Figure 1. Samples were prepared by precipitating protein in aqueous perchloric acid/acetonitrile $(1: 1, \mathrm{v} / \mathrm{v})$ and centrifuging the suspension at $12,000 \mathrm{rpm}$ for 5 $\min$ at $4^{\circ} \mathrm{C}$. The supernatants were directly injected into the HPLC system. To separate cephradine and IS from the endogenous plasma matrix, we used a reverse-phase column. This column offered improved separation for compounds such as $\beta$-lactam antibiotics that were difficult to analyze with other columns.

The following chromatograms were shown in Figure 2: (a) double blank plasma without cephradine and IS, (b) blank plasma with $200 \mu \mathrm{g} / \mathrm{mL}$ of IS, (c) blank plasma spiked with $0.3 \mu \mathrm{g} / \mathrm{mL}$ (LLOQ) of a calibration standard of cephradine and $200 \mu \mathrm{g} / \mathrm{mL}$ of IS, and (d) human plasma taken $1.5 \mathrm{~h}$ after a single oral dose of cephradine (500 mg tablet) and spiked with $200.0 \mu \mathrm{g} / \mathrm{mL}$ of IS. The retention times of cephradine and IS were $4.13 \mathrm{~min}$ and $5.55 \mathrm{~min}$, respectively, none of the blank plasmas yielded any significant endogenous peaks in the cephradine or IS retention times (Figure 2(a)). Our HPLC method was showed short run time (7 min) than previous methods (10 - $28 \mathrm{~min}$ ) [15]-[22] (Table 1).

\subsection{Method Validation and Linearity of Calibration}

A calibration curve was constructed from the peak area ratios of cephradine against IS by using a double-blank sample (plasma sample without cephradine 


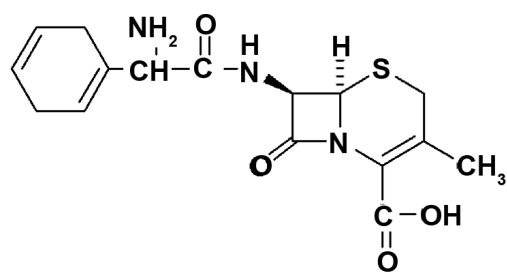

(a) Cephradine $\left(\mathrm{C}_{16} \mathrm{H}_{19} \mathrm{~N}_{3} \mathrm{O}_{4} \mathrm{~S}\right)$<smiles>CC1COc2c(N3CCN(C)CC3)c(F)cc3c(=O)c(C(=O)O)cn1c23</smiles>

(b) Ofloxacin (IS, $\mathrm{C}_{18} \mathrm{H}_{20} \mathrm{FN}_{3} \mathrm{O}_{4}$ )

Figure 1. Chemical structures of (a) Cephradine and (b) Ofloxacin (internal standard).

or IS) and seven calibration standard concentrations $(0.3 \sim 50 \mu \mathrm{g} / \mathrm{mL})$. The standard calibration curve was indicated good linearity within the range of 0.3 $50 \mu \mathrm{g} / \mathrm{mL}$ by least-squares regression analysis $\left(y=0.0521, x-0.0022, r^{2}=\right.$ $0.9999,1 / x^{2}$ weighting). Intra- and inter-day precision and accuracy were determined by analyzing QC samples against the calibration curve, on the same day $(n=5)$ and on different days $(n=5)$. As indicated in Table 2, intra- and inter-day precisions were $3.27 \%-4.75 \%$ and $4.56 \%-6.22 \%$, respectively, and intra- and inter-day accuracies were $99.71 \%-105.65 \%$ and $97.48 \%-99.86 \%$, respectively. The LLOQ was decided to accept the $0.3 \mu \mathrm{g} / \mathrm{mL}$ under the analytical conditions of the precision and accuracy less than 20\% [28]. Therefore, our research was yielded sufficiently the analytical method for pharmacokinetics and bioequivalence studies.

\subsection{Pharmacokinetics and Bioequivalence}

The proposed method was applied to the determination of cephradine in plasma samples for the purpose of establishing the pharmacokinetic and bioequivalence study of $500 \mathrm{mg}$ cephradine formulations in 24 healthy Korean volunteers [42]. The demographic characteristics for each of the healthy volunteers studied are given in Table 3 . There were 22 men and 2 women. Subjects were randomly assigned to receive the reference or test formulation.

The PK parameters for the reference and test drug obtained were described as follows. The first sampling time of 24 subjects were measurable at $0.25 \mathrm{~h}$ after oral administration of cephradine. The profiles of the plasma cephradine concentration vs time were shown in Figure 3. Even though the bioavailability of orally administered cephradine is characterized by considerable individual variation, plasma concentration-time profiles of the two formulations were similar patterns.

The PK parameters of cephradine were shown in Table 4 and Table 5 . In previous studies [2] [13] [23] [27] (Table 5), the PK data of cephradine after oral administration were rapid with $0.80-1.25 \mathrm{~h}$ of $\mathrm{T}_{\max }, 0.61-0.95 \mathrm{~h}$ of half-life $\left(\mathrm{T}_{1 / 2}\right), 12.11-17.7 \mu \mathrm{g} / \mathrm{mL}$ of $C_{\max }$, and $23.14-27.52 \mu \mathrm{g} \cdot \mathrm{h} / \mathrm{mL}$ of $\mathrm{AUC}_{\infty}$ under similar conditions. The mean $\mathrm{T}_{\max }$ values under different conditions of cephradine $1 \mathrm{~kg}$ and $250 \mathrm{mg}$ were $1.12 \pm 0.24 \mathrm{~h}$ and $0.76 \pm 0.12 \mathrm{~h}$, respectively [2] [22]. Our results agreed well with these parameter values. Therefore, it means that there were no difference between Korean subject and the other races. 
H.-J. Kim et al.
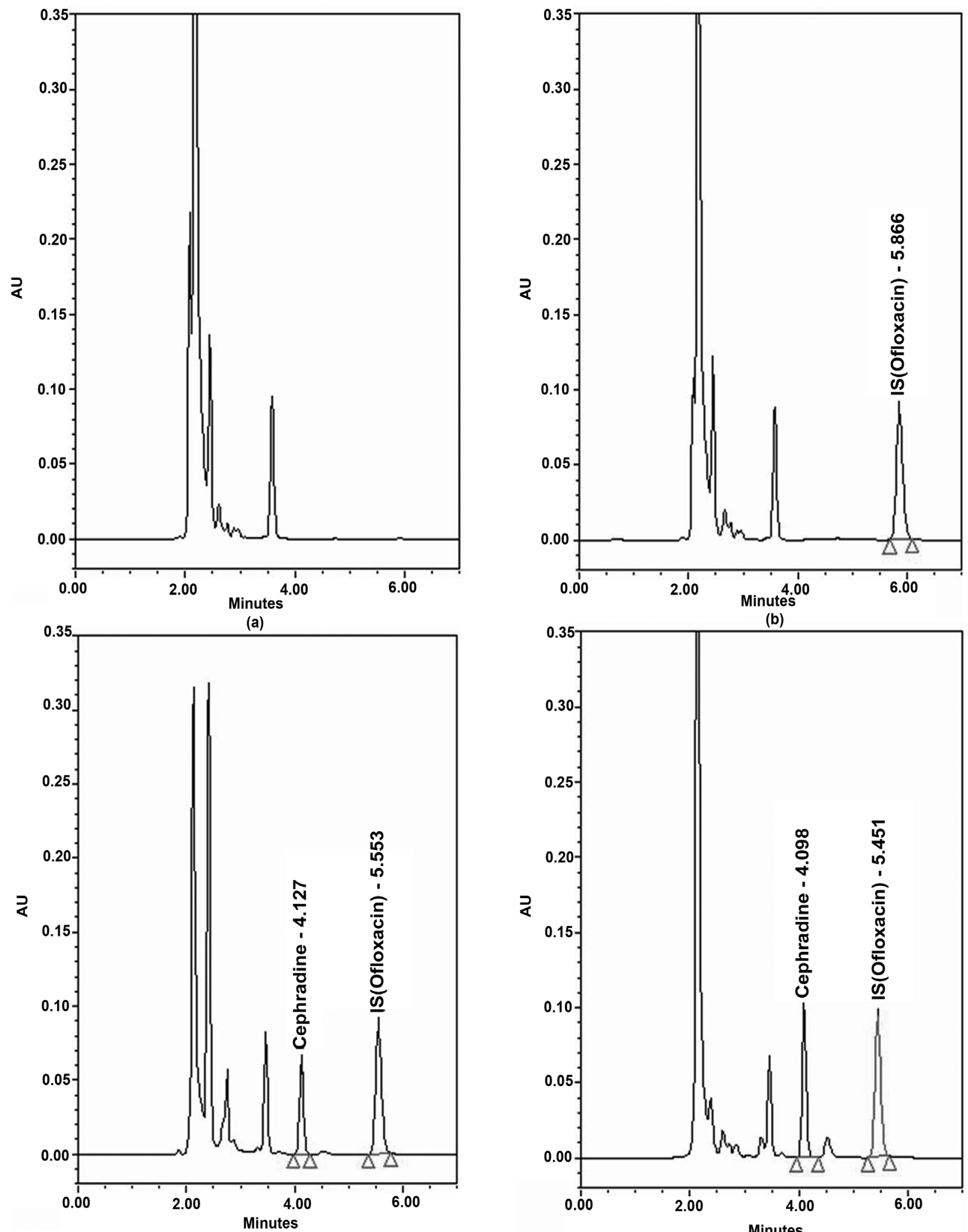

(c)

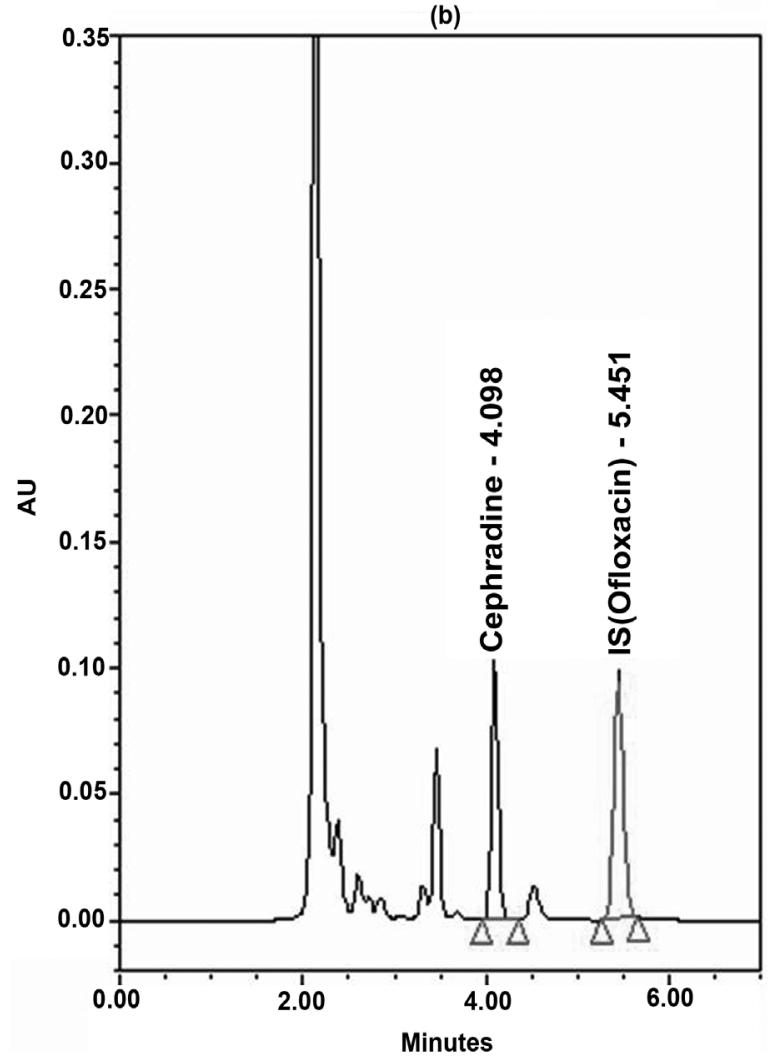

(d)

Figure 2. Chromatograms of (a) Double-blank plasma without cephradine or IS, (b) Blank plasma with IS (200 $\mu$ g/mL), (c) Blank plasma spiked with cephradine (LLOQ, $0.3 \mu \mathrm{g} / \mathrm{mL}$ ) and IS $(200 \mu \mathrm{g} / \mathrm{mL}$ ), and (d) A subject's plasma taken $1.5 \mathrm{~h}$ after a single oral cephradine $500 \mathrm{mg}$ capsule and spiked with IS $(200.0 \mu \mathrm{g} / \mathrm{mL})$. 


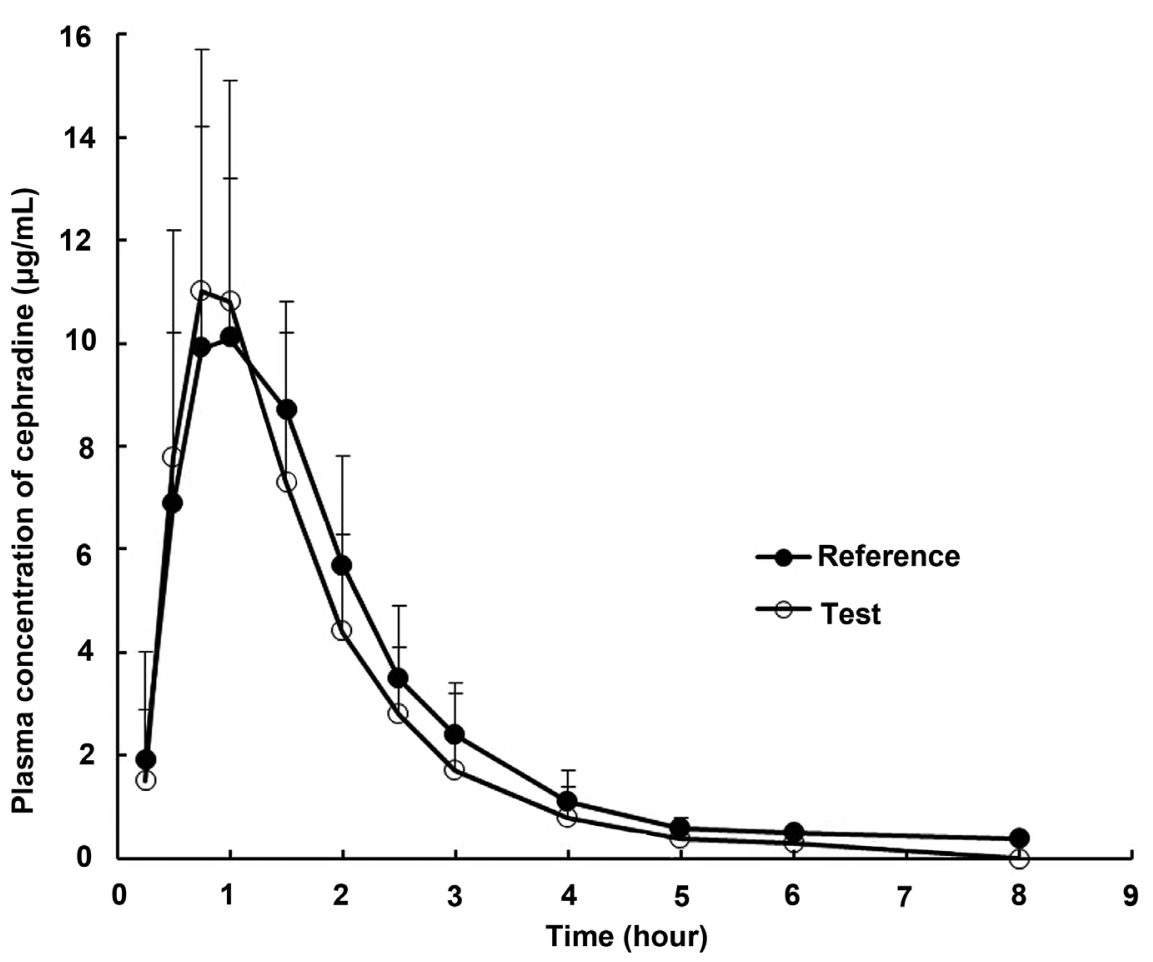

Figure 3. Mean plasma concentrations versus time after single oral cephradine $500 \mathrm{mg}$ capsules were given to 24 healthy subjects $(\bullet$ : reference, $\circ$ : test $)(n=24$, mean \pm SD).

Table 1. Comparison of HPLC methods from articles.

\begin{tabular}{ccccc}
\hline Applied Method & LOD & Linearity & Run times & Sample type \\
\hline Cho HY et al. 2002 [3] & $0.2 \mu \mathrm{g} / \mathrm{mL}$ & $0.2-30.0 \mu \mathrm{g} / \mathrm{mL}$ & $10 \mathrm{~min}$ & Human plasma \\
Johnson VM et al. $2000[15]$ & $0.2 \mu \mathrm{g} / \mathrm{mL}$ & $0.2-30.0 \mu \mathrm{g} / \mathrm{mL}$ & $18 \mathrm{~min}$ & Human plasma \\
Shoaib MH et al. $2008[22]$ & $0.4 \mu \mathrm{g} / \mathrm{mL}$ & $1-12 \mu \mathrm{g} / \mathrm{mL}$ & $28 \mathrm{~min}$ & Human plasma \\
\hline
\end{tabular}

Table 2. Validation of the method for analyzing cephradine in human plasma $(n=5)$.

\begin{tabular}{ccccc}
\hline Nominal Concentration & \multicolumn{2}{c}{ Precision $(\% \mathrm{CV})$} & \multicolumn{2}{c}{ Accuracy (\%) } \\
\hline$(\mu \mathrm{g} / \mathrm{mL})$ & Intra-day & Inter-day & Intra-day & Inter-day \\
\hline $0.3(\mathrm{LLOQ})$ & 4.15 & 6.22 & 99.71 & 97.48 \\
1 (low) & 3.71 & 4.83 & 105.53 & 99.07 \\
$10($ middle) & 4.75 & 5.43 & 105.65 & 99.86 \\
50 (high) & 3.27 & 4.56 & 103.01 & 97.86 \\
\hline
\end{tabular}

LLOQ = lower limit of quantification, $\mathrm{CV}=$ coefficient of variation.

In order of the reference and test formulation of cephradine, $C_{\max }$ were 12.69 and $12.81 \mu \mathrm{g} / \mathrm{mL}$ and $\mathrm{T}_{\max }$ were 1.22 and $0.92 \mathrm{~h}$, respectively. The mean $\mathrm{AUC}_{0-t}$ values were 20.54 and $18.42 \mu \mathrm{g} \cdot \mathrm{h} / \mathrm{mL}$ and the mean $\mathrm{AUC}_{0-\infty}$ values were 21.22 and $19.14 \mu \mathrm{g} \cdot \mathrm{h} / \mathrm{mL}$. In addition, the other PK parameters of two formulations of $500 \mathrm{mg}$ cephradine after oral administration were as follows. The mean $\mathrm{AUMC}_{\mathrm{t}}$ 
Table 3. Demographic Characteristics and sequence of drug administration of the 24 healthy volunteers that participated in the study. (R: Reference drug, T: Test drug).

\begin{tabular}{|c|c|c|c|c|c|}
\hline Subject & $\begin{array}{c}\text { Gender } \\
(\mathrm{M} / \mathrm{F})\end{array}$ & $\begin{array}{c}\text { Age } \\
\text { (years) }\end{array}$ & $\begin{array}{l}\text { Height } \\
(\mathrm{cm})\end{array}$ & $\begin{array}{c}\text { Weight } \\
(\mathrm{kg})\end{array}$ & Sequence \\
\hline 1 & M & 24 & 173.1 & 65.6 & T-R \\
\hline 2 & M & 26 & 175 & 50.6 & T-R \\
\hline 3 & M & 26 & 174.5 & 66.3 & T-R \\
\hline 4 & M & 33 & 173.3 & 55.2 & T-R \\
\hline 5 & $\mathrm{~F}$ & 30 & 157.1 & 47 & $\mathrm{R}-\mathrm{T}$ \\
\hline 6 & M & 23 & 175 & 62 & $\mathrm{R}-\mathrm{T}$ \\
\hline 7 & M & 26 & 171.7 & 60.4 & $R-T$ \\
\hline 8 & $\mathrm{M}$ & 19 & 178.8 & 84 & R-T \\
\hline 9 & M & 25 & 176 & 66 & R-T \\
\hline 10 & M & 27 & 181.7 & 69 & T-R \\
\hline 11 & $\mathrm{~F}$ & 35 & 159.3 & 55.8 & R-T \\
\hline 12 & M & 25 & 176 & 92 & $\mathrm{R}-\mathrm{T}$ \\
\hline 13 & M & 24 & 176 & 74 & R-T \\
\hline 14 & M & 23 & 173 & 75 & $R-T$ \\
\hline 15 & M & 25 & 168.6 & 61 & T-R \\
\hline 16 & M & 23 & 170.2 & 61.5 & T-R \\
\hline 17 & M & 24 & 174.5 & 68.5 & T-R \\
\hline 18 & M & 24 & 179.7 & 79.3 & T-R \\
\hline 19 & M & 27 & 176.6 & 78.6 & R-T \\
\hline 20 & M & 29 & 169.7 & 62.1 & T-R \\
\hline 21 & M & 24 & 177.5 & 87.5 & T-R \\
\hline 22 & M & 25 & 177.9 & 75.8 & R-T \\
\hline 23 & M & 35 & 167.9 & 68.7 & $\mathrm{R}-\mathrm{T}$ \\
\hline 24 & $\mathrm{M}$ & 28 & 167.5 & 72.7 & T-R \\
\hline
\end{tabular}

values were 39.34 and $28.56 \mu \mathrm{g} \cdot \mathrm{h}^{2} / \mathrm{mL}$, and $\mathrm{AUMC}_{\infty}$ values were 39.93 and $33.47 \mu \mathrm{g} \cdot \mathrm{h}^{2} / \mathrm{mL}$ for the reference and test drug. The mean MRT value obtained for the reference and test drug were 1.86 and $1.73 \mathrm{~h}$, respectively. These parameters almost overlapped between the test and reference drugs (Table 4).

The $90 \%$ CI of the test/reference percentage ratio were $90.6 \%(86.64 \%$ 97.74\%) for $\mathrm{AUC}_{0-t}$ and $102.3 \%$ (91.06\% - 114.84\%) for $C_{\max }$, both of which were within the bioequivalence limits of $80 \%-125 \%$ for the percentage ratio of product averages. These results support that the two branded formulations of $500 \mathrm{mg}$ cephradine capsules were bioequivalent. Since we evaluated the minimum number of healthy adult subjects, this study has no consideration for all ages and gender. 
Table 4. Pharmacokinetic parameters (mean \pm SD) of two formulations of cephradine 500 mg capsules based on plasma concentrations in 24 healthy subjects.

\begin{tabular}{ccc}
\hline Parameters & Reference drug & Test drug \\
\hline $\mathrm{AUC}_{t}(\mu \mathrm{g} \cdot \mathrm{h} / \mathrm{mL})$ & $20.54 \pm 4.30$ & $18.42 \pm 2.96$ \\
$\mathrm{AUC}_{\infty}(\mu \mathrm{g} \cdot \mathrm{h} / \mathrm{mL})$ & $21.22 \pm 4.38$ & $19.14 \pm 3.06$ \\
Extrapolated $\mathrm{AUC}(\%) \mathrm{AUMC}_{t}\left(\mu \mathrm{g} \cdot \mathrm{h}^{2} / \mathrm{mL}\right)$ & $3.22 \pm 1.05$ & $3.75 \pm 1.73$ \\
$\mathrm{AUMC}_{\infty}\left(\mu \mathrm{g} \cdot \mathrm{h}^{2} / \mathrm{mL}\right)$ & $35.34 \pm 13.56$ & $28.56 \pm 7.88$ \\
$\mathrm{Vd}(\mathrm{L})$ & $39.93 \pm 15.37$ & $33.47 \pm 9.19$ \\
$\mathrm{MRT} \mathrm{h})$ & $36.68 \pm 11.25$ & $45.18 \pm 20.68$ \\
$C_{\max }(\mu \mathrm{g} / \mathrm{mL})$ & $1.86 \pm 0.39$ & $1.73 \pm 0.29$ \\
$\mathrm{~T}_{1 / 2 \alpha}(\mathrm{h})$ & $12.69 \pm 3.27$ & $12.81 \pm 2.80$ \\
$\mathrm{~T}_{\max }(\mathrm{h})$ & $0.29 \pm 0.15$ & $0.40 \pm 0.27$ \\
$\mathrm{k}_{\alpha}\left(\mathrm{h}^{-1}\right)$ & $1.22 \pm 0.57$ & $0.92 \pm 0.32$ \\
$\mathrm{~T}_{1 / 2 \beta}(\mathrm{h})$ & $3.23 \pm 2.64$ & $2.46 \pm 1.58$ \\
$\lambda_{z}\left(\mathrm{k}_{\mathrm{e}}, \mathrm{h}^{-1}\right)$ & $1.02 \pm 0.31$ & $1.13 \pm 0.57$ \\
$\mathrm{CL}_{(\mathrm{L} / \mathrm{h})}$ & $0.73 \pm 0.17$ & $0.69 \pm 0.19$
\end{tabular}

$\mathrm{AUC}_{t}=$ area under the plasma concentration-time curve from time 0 to time $t, \mathrm{AUC}_{\infty}=$ area under the plasma concentration-time curve from time 0 to infinite time, $\mathrm{AUMC}_{t}=$ area under the first moment of the plasma concentration-time curve from time 0 to time $t$, $\mathrm{AUMC}_{\infty}=$ area under the first $\mathrm{moment}$ of the plasma concentration-time curve from time 0 to infinite time, $\mathrm{Vd}=$ the apparent volume of distribution, $\mathrm{MRT}=$ the mean residence time, $C_{\mathrm{max}}=$ the maximal plasma concentration, $\mathrm{T}_{1 / 2 \alpha}=$ the half-life of absorption, $\mathrm{T}_{\max }=$ the time to maximal plasma concentration, $\mathrm{k}_{\alpha}=$ the distribution rate constant, $\mathrm{T}_{1 / 2 \beta}$ $=$ the half-life of elimination, $\lambda_{z}\left(\mathrm{k}_{\mathrm{e}}\right)=$ the elimination rate constant, $\mathrm{CL}=$ clearance.

Table 5. Comparison of Pharmacokinetic parameters (mean \pm SD) of cephradine after oral administration in current and previous studies.

\begin{tabular}{|c|c|c|c|c|c|c|c|c|}
\hline Parameters & Country & $\begin{array}{c}\text { Sample } \\
\text { Size }\end{array}$ & $\begin{array}{l}\text { Sampling } \\
\text { Time }\end{array}$ & $\begin{array}{c}\mathrm{AUC}_{t} \\
(\mu \mathrm{g} \cdot \mathrm{h} / \mathrm{mL})\end{array}$ & $\begin{array}{c}\mathrm{AUC}_{\infty} \\
(\mu \mathrm{g} \cdot \mathrm{h} / \mathrm{mL})\end{array}$ & $\begin{array}{c}C_{\max } \\
(\mu \mathrm{g} / \mathrm{mL})\end{array}$ & $\mathrm{T}_{\max }(\mathrm{h})$ & $\mathrm{T}_{1 / 2 \beta}(\mathrm{h})$ \\
\hline Hassanzadeh MK et al. 1999 [1] & Iran & 8 & $6 \mathrm{~h}$ & - & $23.14 \pm 2.3$ & $12.11 \pm 2.7$ & $1.25 \pm 0.4$ & $0.95 \pm 0.2$ \\
\hline Chen ML 1992 [13] & USA & 18 & $10 \mathrm{~h}$ & $24.7 \pm 2.7$ & $25.1 \pm 2.7$ & $17.4 \pm 0.6$ & $0.83 \pm 0.1$ & - \\
\hline Shoaib, MH 2008 [22] & Pakistan & 6 & $7 \mathrm{~h}$ & $16.40 \pm 1.7$ & $16.90 \pm 0.3$ & $11.49 \pm 1.7$ & $0.76 \pm 0.1$ & $0.44 \pm 0.2$ \\
\hline Choi SJ et al. 2009 [23] & Korea & 24 & $6 \mathrm{~h}$ & $26.99 \pm 4.2$ & $27.52 \pm 4.2$ & $16.3 \pm 4.3$ & $1.2 \pm 0.5$ & $0.85 \pm 0.1$ \\
\hline Pfeffer M et al. 1977 [27] & USA & 12 & $12 \mathrm{~h}$ & - & $27.5 \pm 2.2$ & $17.7 \pm 1.2$ & $0.80 \pm 0.1$ & $0.61 \pm 0.1$ \\
\hline
\end{tabular}

\section{Conclusion}

We developed a fast HPLC method to measure cephradine in human plasma. It was based on removing protein by precipitation, and used a high resolution column and a fast isocratic flow rate. This method had similar precision and accuracy to previous methods, whereas, it had indicated more short analysis times (cephradine [ $4.13 \mathrm{~min}$ ], IS [5.55 $\mathrm{min}]$ ) than previous analysis methods. The use of a method with a short retention time was important, particularly for large-scale clinical trials, because it allowed its high throughput. The method was 
successful in a strictly-controlled bioequivalence and pharmacokinetic study of two brands of cephradine $500 \mathrm{mg}$ capsules in 24 normal subjects.

\section{Acknowledgements}

This work was supported by the National Research Foundation of Korea (NRF) grant funded by the Korea government (MSIP; Ministry of Science, ICT \& Future Planning) (No. 2017R1A6A3A11033084).

\section{Conflicts of Interest}

The authors declare no conflicts of interest regarding the publication of this paper.

\section{References}

[1] Hassanzadeh, M.K. and Afzali, S.F.B.S. (1999) Comparative Bioavailability of Four Oral Formulation of Cephradine Capsules. DARU Journal of Pharmaceutical Sciences, 7, 15-18.

[2] Schwinghammer, T.L., Norden, C.W. and Gill, E. (1990) Pharmacokinetics of Cephradine Administered Intravenously and Orally to Young and Elderly Subjects. The Journal of Clinical Pharmacology, 30, 893-899. https://doi.org/10.1002/j.1552-4604.1990.tb03568.x

[3] Cho, H.Y., Lee, S., Kang, H.A., Oh, I.J., Lim, D.K., Moon, J.D. and Lee, Y.B. (2002) Bioequivalence of Broadcef Capsule to Cefradine Yuhan Capsule (Cephradine 500 mg). Journal of Pharmaceutical Investigation, 32, 215-221. https://doi.org/10.4333/KPS.2002.32.3.215

[4] Ródenas, V., García, M.S., Sánchez-Pedreño, C. and Albero, M.I. (1997) Spectrophotometric Methods for the Determination of Cephradine or Ceftazidine in $\mathrm{Hu}$ man Urine Using Batch and Flow-Injection Procedures. Journal of Pharmaceutical and Biomedical Analysis, 15, 1687-1693. https://doi.org/10.1016/S0731-7085(96)01963-2

[5] Al-Ghabsha, T.S., Al-Sabha, T. and Al-Mtaiwti, S.M. (2007) Spectrophotometric Determination of Cephradine and Cefadroxil Using 2,3-Dichloro-5,6-Dicyano-1,4Benzoquinone Reagent. University of Sharjah Journal of Pure \& Applied Sciences, 4, 13-28.

[6] Al-Momani, I. (2004) Flow-Injection Spectrophotometric Determination of Amoxcillin, Cephalexin, Ampicillin, and Cephradine in Pharmaceutical Formulations. Analytical Letters, 37, 2099-2110. https://doi.org/10.1081/AL-200026683

[7] Yang, J., Zhou, G., Cao, X., Ma, Q. and Dong, J. (1998) Study on the Fluorescence Characteristics of Alkaline Degradation of Cefadroxil, Cephradine, Cefotaximum Sodium and Amoxicillini. Analytical Letters, 31, 1047-1060. https://doi.org/10.1080/00032719808002841

[8] Hefnawy, M., El-Shabrawy, Y. and Belal, F. (1999) Spectrofluorometric Determination of Alpha-Aminocephalosporins in Biological Fluids and Pharmaceutical Preparations. Journal of Pharmaceutical and Biomedical Analysis, 21, 703-707. https://doi.org/10.1016/S0731-7085(99)00208-3

[9] Yang, J., Ma, Q., Wu, X., Sun, L. and Cao, X. (1999) A New Luminescence Spectrometry for the Determination of Some $\beta$-Lactamic Antibiotics. Analytical letters, 32 , 471-480. https://doi.org/10.1080/00032719908542834 
[10] Li, Y. and Lu, J. (2006) Chemiluminescence Flow-Injection Analysis of $\beta$-Lactam Antibiotics Using the Luminol-Permanganate Reaction. Luminescence, 21, 251-255. https://doi.org/10.1002/bio.915

[11] Emaldi, P., Fapanni, S. and Baldini, A. (1995) Validation of a Capillary Electrophoresis Method for the Determination of Cephradine and Its Related Impurities. Journal of Chromatography A, 711, 339-346. https://doi.org/10.1016/0021-9673(95)00520-W

[12] Kramer, J. (1968) Antibiotic Residues in Milk, Dairy Products, and Animal Tissues: Methods, Reports, and Protocols. Department of Health, Education, and Welfare, National Center for Antibiotic and Insulin Analysis, Food and Drug Administration.

[13] Chen, M.L. (1992) An Alternative Approach for Assessment of Rate of Absorption in Bioequivalence Studies. Pharmaceutical Research, 9, 1380-1385. https://doi.org/10.1023/A:1015842425553

[14] Leary, W., Asmal, A., Lockett, C. and Bima, B. (1975) A Preliminary Report on Cephradine. South African Medical Journal, 49, 1356-1358.

[15] Johnson, V.M., Allanson, J.P. and Causon, R.C. (2000) Determination of the Cephalosporin Antibiotic Cephradine in Human Plasma by High-Performance Liquid Chromatography with Ultraviolet Detection. Journal of Chromatography B: Biomedical Sciences and Applications, 740, 71-80. https://doi.org/10.1016/S0378-4347(00)00023-2

[16] Samanidou, V.F., Hapeshi, E.A. and Papadoyannis, I.N. (2003) Rapid and Sensitive High-Performance Liquid Chromatographic Determination of Four Cephalosporin Antibiotics in Pharmaceuticals and Body Fluids. Journal of Chromatography B, 788, 147-158. https://doi.org/10.1016/S1570-0232(02)01040-1

[17] Jandik, P., Weigl, B.H., Kessler, N., Cheng, J., Morris, C.J., Schulte T. and Avdalovic N. (2002) Initial Study of Using a Laminar Fluid Diffusion Interface for Sample Preparation in High-Performance Liquid Chromatography. Journal of Chromatography A, 954, 33-40. https://doi.org/10.1016/S0021-9673(02)00160-7

[18] Hendrix, C., Yongxin, Z., Pijcke, M., Roets, E. and Hoogmartens, J. (1993) A Comparative Study of LC Methods for Analysis of Cefradine. Journal of Pharmaceutical and Biomedical Analysis, 11, 595-599. https://doi.org/10.1016/0731-7085(93)80010-X

[19] Hendrix, C., Pijcke, M., Yun, L.M., Roets, E. and Hoogmartens, J. (1993) Quantitative Analysis of Cefradine by Liquid Chromatography on Poly (Styrene-Divinylbenzene). Journal of Pharmaceutical and Biomedical Analysis, 11, 145-155. https://doi.org/10.1016/0731-7085(93)80135-N

[20] Huang, H.S., Wu, J.R. and Chen, M.L. (1991) Reversed-Phase High-Performance Liquid Chromatography of Amphoteric $\beta$-Lactam Antibiotics: Effects of Columns, Ion-Pairing Reagents and Mobile Phase $\mathrm{pH}$ on Their Retention Times. Journal of Chromatography B: Biomedical Sciences and Applications, 564, 195-203. https://doi.org/10.1016/0378-4347(91)80081-M

[21] Mcateer, J.A., Hiltke, M.F., Silber, B. and Faulkner, R. (1987) Liquid-Chromatographic Determination of Five Orally Active Cephalosporins-Cefixime, Cefaclor, Cefadroxil, Cephalexin, and Cephradine-In Human Serum. Clinical Chemistry, 33, 1788-1790.

[22] Shoaib, M.H., Shaikh, D., Yousuf, R.I., Naqvi, B.S. and Hashmi, K. (2008) Pharmacokinetic Study of Cephradine in Pakistani Healthy Male Volunteers. Pakistan Journal of Pharmaceutical Sciences, 21, 400-406. 
[23] Choi, S.J., Ryu, J.H., Lee, H.W., Lee, M.J., Seo, J.H., Tak, S.K. and Lee, K.T. (2009) Rapid and Simple Method for Determination of Cephradine in Human Plasma Using Liquid Chromatography-Tandem Mass Spectrometry (LC-MS/MS): Application to the Bioequivalence Study. Journal of Chromatography B, 877, 4059-4064. https://doi.org/10.1016/j.jchromb.2009.10.011

[24] Chen, X., Zhong, D., Huang, B. and Cui, J. (2003) Determination of Cefaclor in Human Plasma by a Sensitive and Specific Liquid Chromatographic-Tandem Mass Spectrometric Method. Journal of Chromatography B, 784, 17-24. https://doi.org/10.1016/S1570-0232(02)00656-6

[25] Nightingale, S.L. and Morrison, J.C. (1987) Generic Drugs and the Prescribing Physician. Journal of the American Medical Association, 258, 1200-1204. https://doi.org/10.1001/jama.1987.03400090084039

[26] Olson, S.C., Eldon, M.A., Toothaker, R.D., Ferry, J.J. and Colburn, W.A. (1987) Controversy II: Bioequivalence as an Indicator of Therapeutic Equivalence: Modeling the Theoretic Influence of Bioinequivalence on Single-Dose Drug Effect. The Journal of Clinical Pharmacology, 27, 342-345. https://doi.org/10.1002/j.1552-4604.1987.tb03029.x

[27] Pfeffer, M., Jackson, A., Ximenes, J. and De Menezes, J.P. (1977) Comparative Human Oral Clinical Pharmacology of Cefadroxil, Cephalexin, and Cephradine. Antimicrobial Agents and Chemotherapy, 11, 331-338. https://doi.org/10.1128/AAC.11.2.331

[28] Food and Administration (2001) FDA Guidance for Industry: Bioanalytical Method Validation. US Department of Health and Human Services, Food and Drug Administration, Center for Drug Evaluation and Research, Rockville, 124-129.

[29] Chow, S.C. and Liu, J.P. (2008) In Design and Analysis of Bioavailability and Bioequivalence Studies. 3rd Edition, Chapman and Hall/CRC, London.

[30] Goodyear, M.D.E., Krleza-Jeric, K. and Lemmens, T. (2007) The Declaration of Helsinki. BMJ: British Medical Journal, 335, 624-625. https://doi.org/10.1136/bmj.39339.610000.BE

[31] Kim, M.S., Park, Y.S., Kim, S.H., Kim, S.Y., Lee, M.H., Kim, Y.H., Kim, D.W., Yang, S.C. and Kang, J.S. (2012) Quantification of Nimesulide in Human Plasma by High-Performance Liquid Chromatography with Ultraviolet Detector (HPLC-UV): Application to Pharmacokinetic Studies in 28 Healthy Korean Subjects. Journal of Chromatographic Science, 50, 396-400. https://doi.org/10.1093/chromsci/bms014

[32] Kang, C.N., Kim, H.J., Park, Y.S., Kim, S.H., Park, H.K., Hwang, H.S. and Kang, J.S. (2014) A Simple and Rapid LC-MS/MS Method for the Determination of Enalapril in Human Plasma for Pharmacokinetic and Bioequivalence Studies in Korean Healthy Volunteers under Fasting Conditions. Journal of Analytical Chemistry, 69, 467-473. https://doi.org/10.1134/S1061934814050049

[33] Kim, S.Y., Song, I.D., Kim, H.J., Park, Y.S., Kim S.H., Kang, M.A., Kim, D.W. and Kang, J.S. (2015) Quantification of Ciprofloxacin in Human Plasma by Validated LC-MS/MS Using Ofloxacin as an Internal Standard and Its Clinical Application. Current Pharmaceutical Analysis, 11, 239-247. https://doi.org/10.2174/1573412911666150331224024

[34] Park, Y.S., Kim ,S.H., Kim, S.Y., Kim, Y.H., Lee, M.H., Yang, S.C., Shaw, L.M. and Kang, J.S. (2012) Quantification of Galantamine in Human Plasma by Validated Liquid Chromatography-Tandem Mass Spectrometry Using Glimepride as an Internal Standard: Application to Bioavailability Studies in 32 Healthy Korean Subjects. Journal of Chromatographic Science, 50, 803-809. 
https://doi.org/10.1093/chromsci/bms074

[35] Park, J.H., Park, Y.S., Rhim, S.Y., Kim, H.J., Jhee, O.H., Lee, Y.S., Lee, M.H., Shaw, L.M. and Kang, J.S. (2009) Rapid Quantification of Levosulpiride in Human Plasma Using RP-HPLC-MS/MS for Pharmacokinetic and Bioequivalence Study. Biomedical Chromatography, 23, 1350-1356. https://doi.org/10.1002/bmc.1260

[36] Park, Y.S., Kim, S.H., Kim, Y.J., Yang, S.C., Lee, M.H., Shaw, L.M. and Kang, J.S. (2010) Determination of Azelastine in Human Plasma by Validated Liquid Chromatography Coupled to Tandom Mass Spectrometry (LC-ESI/MS/MS) for the Clinical Studies. International Journal of Biomedical Science: IJBS, 6, 120.

[37] Jhee, O.H., Lee, Y.S., Shaw, L.M., Jeon, Y.C., Lee, M.H., Lee, S.H. and Kang, J.S. (2007) Pharmacokinetic and Bioequivalence Evaluation of Two Formulations of 100 mg Trimebutine Maleate ${\left(\text { Recutin }^{\mathrm{TM}}\right.}$ and Polybutin ${ }^{\mathrm{Tm}}$ ) in Healthy Male Volunteers Using the LC-MS/MS Method. Clinica Chimica Acta, 375, 69-75.

https://doi.org/10.1016/j.cca.2006.06.006

[38] Rhim, S.Y., Park, J.H., Park, Y.S., Lee, M.H., Hwang, K.G., Kim, Y.S., Shaw, L.M., Lee, Y.S. and Kang, J.S. (2009) Pharmacokinetics and Bioequivalence of $20 \mathrm{mg}$ Omeprazole Capsule in 24 Healthy Korean Male Volunteers. International Journal of Clinical Pharmacology and Therapeutics, 47, 23-29. https://doi.org/10.5414/CPP47023

[39] KFDA (2007) Guidance Document for Bioequivalence Study. Department of Food \& Drug Safety Notification No. \#2007-65.

[40] Farrier, D.S. (2005) PK Solutions 2.0; Pharmacokinetics Data Analysis User Guide, Summit Research Services USA.

[41] Baek, I.H., Seong, S.H. and Kwon, K.I. (2009) Bioequivalence Approaches for Highly Variable Drugs: Issue and Solution. Korean Journal of Clinical Pharmacy, $19,50-60$.

[42] FDA (2003) Guidance for Industry: "Bioavailability and Bioequivalence Studies for Orally Administered Drug Products-General Considerations”. Food and Drug Administration, Rockville. 